$16^{\text {th }}$ International Conference on

AEROSPACE SCIENCES \& AVIATION TECHNOLOGY,

ASAT - 16 - May 26 - 28, 2015, E-Mail: asat@mtc.edu.eg

Military Technical College, Kobry Elkobbah, Cairo, Egypt

Tel : +(202) 24025292 - 24036138, Fax: +(202) 22621908

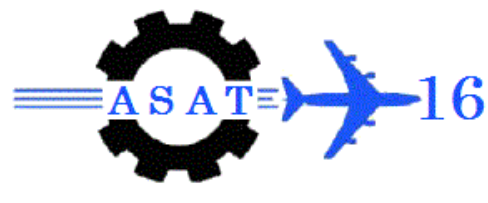

\title{
Investigation of the Ride Response of a Multi-wheeled Combat Vehicle in Pitch-Bounce Plane
}

\author{
M. Mohsen ${ }^{*}$, H. M. Eltaher ${ }^{\dagger}$, A. M. Sharaf ${ }^{*}$ and S. M. El-demerdash ${ }^{\S}$
}

\begin{abstract}
Recently there is a worldwide trend to transform the heavy troops into more agile and deployable forces. These forces are based on light armored multi-wheeled combat vehicles which are demanding several challenging requirements. Furthermore, the design of suspension system of these vehicles is complex and should provide several conflicting issues such as higher mobility and cornering stability whilst maintaining a sufficient ride comfort for the crew. This paper presents a comprehensive investigation of the ride response of a typical combat vehicle in pitch-bounce plan under the effect of random road excitation. A set of mathematical passive suspension models for the vehicle with different configurations including two-axle, three-axle and four-axle are derived. The numerical simulation is carried out through the MATLAB/SIMULINK environment which aids the future development of controllable suspension systems. The ride responses of the vehicle is obtained and analyzed considering the vibration isolation, suspension deflection, and road-holding. The results show an improvement in the responses of vehicle body vertical acceleration, pitch acceleration and dynamic tire load using four-axle vehicle configuration over three-axle and two-axle ones.
\end{abstract}

Keywords: Vehicle ride dynamics, suspension system, half car model.

\section{Nomenclatures}

$a$

$b$

$C_{s f 1}, C_{s f 2}$

$C_{s r 1}, C_{s r 2}$

$C_{t f 1}, C_{t f 2}$

$C_{t r 1}, C_{t r 2}$

$c$

$d$

$I_{b}$
Longitudinal distance from vehicle body CG to the first front axle $(\mathrm{m})$

Longitudinal distance from vehicle body CG to the second front axle $(\mathrm{m})$

Suspension damping coefficients of the first and second front axles $(\mathrm{Ns} / \mathrm{m})$

Suspension damping coefficients of the first and second rear axles $(\mathrm{Ns} / \mathrm{m})$

Tire damping coefficients of the first and second front axles $(\mathrm{Ns} / \mathrm{m})$

Tire damping coefficients of the first and second rear axles $(\mathrm{Ns} / \mathrm{m})$

Longitudinal distance from vehicle body CG to the second rear axle $(m)$

Longitudinal distance from vehicle body CG to the first rear axle $(\mathrm{m})$

Mass moment of inertia of the vehicle body about lateral axis $\left(\mathrm{kgm}^{2}\right)$

\footnotetext{
* PhD Student, Automotive Engineering Dept., Military Technical College

${ }^{\dagger}$ Lecturer, Automotive Engineering Dept., Military Technical College

¥ Associate Professor, Head of Automotive Engineering Dept., Military Technical College

${ }^{\S}$ Professor, Helwan University, Faculty of Engineering and Technology, Mataria, Cairo, Egypt
} 


\begin{tabular}{|c|c|}
\hline$K_{s f 1}, K_{s f 2}$ & Suspension spring stiffness of the first and second front axles $(\mathrm{N} / \mathrm{m})$ \\
\hline$K_{s r 1}, K_{s r 2}$ & Suspension spring stiffness of the first and second rear axles $(\mathrm{N} / \mathrm{m})$ \\
\hline$K_{t f 1}, K_{t f 2}$ & Tire vertical stiffness of the first and second front axles $(\mathrm{N} / \mathrm{m})$ \\
\hline$K_{t r 1}, K_{t r 2}$ & Tire vertical stiffness of the first and second rear axles $(\mathrm{N} / \mathrm{m})$ \\
\hline$M_{b}$ & Vehicle body mass $(\mathrm{kg})$ \\
\hline$M_{w f 1}, M_{w f 2}$ & Front axles masses $(\mathrm{kg})$ \\
\hline$M_{w r 1}, M_{w r 2}$ & Rear axles masses $(k g)$ \\
\hline$V$ & Vehicle forward speed $(\mathrm{m} / \mathrm{s})$ \\
\hline$W_{n}$ & White noise with intensity $2 \sigma^{2} \rho V$ \\
\hline$x_{f 1}, x_{f 2}$ & Ground input displacement at the first and second front axles $(\mathrm{m})$ \\
\hline$x_{r 1}, x_{r 2}$ & Ground input displacement at the first and second rear axles $(m)$ \\
\hline$z_{b}$ & Vehicle body vertical displacement at CG $(m)$ \\
\hline$z_{w f 1}, z_{w f 2}$ & Vertical displacements of the first and second front axles $(\mathrm{m})$ \\
\hline$z_{w r 1}, z_{w r 2}$ & Vertical displacements of the first and second rear axles $(m)$ \\
\hline$\theta$ & Vehicle body pitch angle $(\mathrm{rad})$ \\
\hline$\rho$ & The road roughness parameter \\
\hline$\sigma$ & The covariance of road irregularity \\
\hline
\end{tabular}

\section{Introduction}

The multi-wheeled all-terrain armored vehicles used in transporting troops need several conflicting requirements such as high stability, comfort ride and road-friendly interaction [1].This type of vehicles is characterized by relatively higher weight and normally driven at higher speed over rough terrains [2]. Additionally, improving ride performance enables the driver to either has a more comfortable ride, and thus be able to drive for longer time and distance or to drive faster at the same level of discomfort [3]. Conventional suspension systems offer a trade-off between ride comfort and vehicle handling, and their performance is often limited by this compromise. Good design of a passive suspension cannot eliminate this trade-off, but can improve ride comfort and vehicle stability [4]. The modeling of a passive and semi-active multi wheeled off-road vehicle has been researched widely by several authors $[3,5]$. Waleed Faris [6] proposed a three mathematical multi-axles semi-active suspension models namely; 2-axle, 3-axle, \& 4-axle. Results show an improvement in ride comfort and vehicle handling using 4-axle over 3-axle and 2-axle when emphasis is placed on the response of the vehicle body acceleration, suspension displacement and tire deflection.

In this paper, three mathematical models of a passive suspension system for two, three and four-axle armored vehicles are developed in MATLAB/SIMULINK environment. A typical 14 ton gross vehicle weight (GVW) armored vehicle, shown in Fig. 1, is used as a case study 
in this work. The total suspension stiffness \& damping for the three different models are considered to be equal. For brevity, only the mathematical model for a four-axle armored vehicle is described here; while the two \& three-axle models are not.

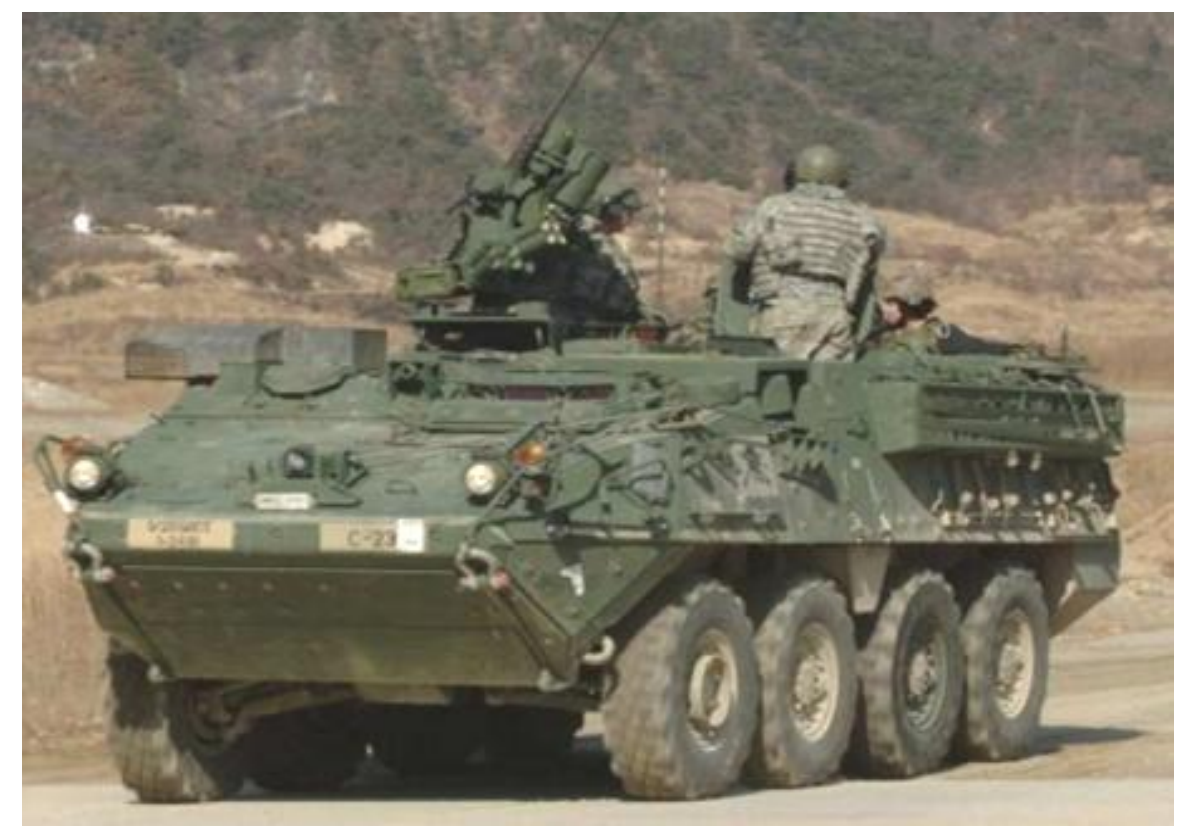

Fig. 1. Four-axle armored vehicle

\section{Model Description}

The multi-wheeled combat vehicle is represented by a mathematical model of total six degrees of freedom (6-DOF) in order to investigate its ride response in pitch-bounce plan as shown in Fig. 2. The vehicle body is assumed to have sprung mass $\left(M_{b}\right)$ and mass moment of inertia $\left(I_{b}\right)$. Accordingly, two vibration modes are considered for the vehicle body namely bounce $\left(z_{b}\right)$ and pitch $\left(\theta_{b}\right)$. The four axles are represented by un-sprung masses ( $\left.M_{w f_{1}}, M_{w f_{2}}, M_{w r_{1}}, M_{w r_{2}}\right)$ such that each axle has a single degree of freedom in the vertical direction $\left(z_{w f_{1}}, z_{w f_{2}}, z_{w r_{1}}, z_{w r_{2}}\right)$. The vehicle body is supported by each axle through a suspension system consist of a linear spring and damper. The suspension springs are represented by an equivalent front and rear linear springs $\left(K_{S f_{1}}, K_{S f_{2}}, K_{S_{1}}, K_{S_{2}}\right)$, while the damping elements are represented by an equivalent front and rear dampers $\left(C_{S_{1}}, C_{S f_{2}}, C_{S_{1}}, C_{S r_{2}}\right.$ ). The tires are represented by linear springs $\left(K_{t f_{1}}, K_{t f_{2}}, K_{t r_{1}}, K_{t r_{2}}\right)$ and viscous dampers ( $\left.C_{t f_{1}}, C_{t f_{2}}, C_{t r_{1}}, C_{t r_{2}}\right)$. The tires are contacted with the load at points which are the sources of the vehicle excitation. The equations of motion for this model can be obtained directly using Newton or Lagrange principles in the following form:

$[M]\{\ddot{Z}\}+[C]\{\dot{Z}\}+[K]\{Z\}=\left[C_{f}\right]\left\{\dot{x}_{0}\right\}+\left[K_{f}\right]\left\{x_{0}\right\}$

Where $[\mathrm{M}],[\mathrm{C}]$ and $[\mathrm{K}]$ are mass, damping and stiffness constant matrices, $\{\mathrm{Z}\}$ is the generalized coordinate vector, $\left\{\mathrm{X}_{0}\right\}$ is a system excitation vector, $\left[\mathrm{C}_{\mathrm{f}}\right]$ and $\left[\mathrm{K}_{\mathrm{f}}\right]$ are damping and stiffness. 


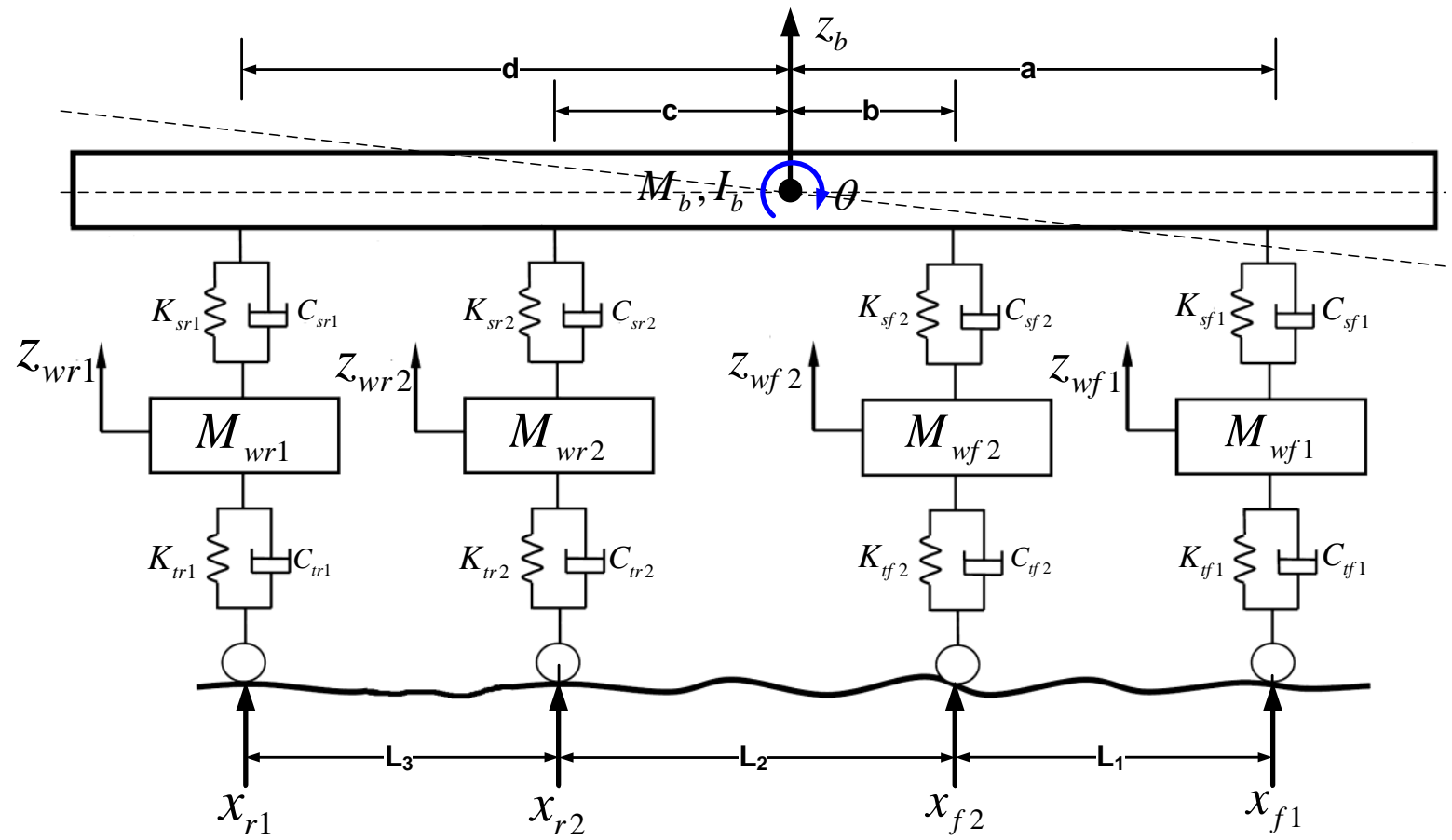

Fig. 2. The Mathematical Model of Multi-wheeled Combat Vehicle in Pitch-Bounce Plane

The equations of motion representing the vehicle body are written as follows:

$$
\begin{aligned}
M_{b} \ddot{z}_{b}= & -K_{s f_{1}}\left(z_{b}-z_{w f_{1}}-a \theta_{b}\right)-C_{s f_{1}}\left(\dot{z}_{b}-\dot{z}_{w f_{1}}-a \dot{\theta}_{b}\right) \\
& -K_{s f_{2}}\left(z_{b}-z_{w f_{2}}-b \theta_{b}\right)-C_{s f_{2}}\left(\dot{z}_{b}-\dot{z}_{w f_{2}}-b \dot{\theta}_{b}\right) \\
& -K_{s r_{2}}\left(z_{b}-z_{w r_{2}}+c \theta_{b}\right)-C_{s r_{2}}\left(\dot{z}_{b}-\dot{z}_{w r_{2}}+c \dot{\theta}_{b}\right) \\
& -K_{s r_{1}}\left(z_{b}-z_{w r_{1}}+d \theta_{b}\right)-C_{s r_{1}}\left(\dot{z}_{b}-\dot{z}_{w r_{1}}+d \dot{\theta}_{b}\right) \\
I_{b} \ddot{\theta}_{b}= & +a\left[K_{s f_{1}}\left(z_{b}-z_{w f_{1}}-a \theta_{b}\right)+C_{s f_{1}}\left(\dot{z}_{b}-\dot{z}_{w f_{1}}-a \dot{\theta}_{b}\right)\right] \\
& +b\left[K_{s f_{2}}\left(z_{b}-z_{w f_{2}}-b \theta_{b}\right)+C_{s f_{2}}\left(\dot{z}_{b}-\dot{z}_{w f_{2}}-b \dot{\theta}_{b}\right)\right] \\
& -c\left[K_{s r_{2}}\left(z_{b}-z_{w r_{2}}+c \theta_{b}\right)+C_{s r_{2}}\left(\dot{z}_{b}-\dot{z}_{w r_{2}}+c \dot{\theta}_{b}\right)\right] \\
& -d\left[K_{s r_{1}}\left(z_{b}-z_{w r_{1}}+d \theta_{b}\right)-C_{s r_{1}}\left(\dot{z}_{b}-\dot{z}_{w r_{1}}+d \dot{\theta}_{b}\right)\right]
\end{aligned}
$$

The equations of motion representing un-sprung mass vertical dynamics are written as follows:

$$
\begin{aligned}
& M_{w f_{1}} \ddot{z}_{w f_{1}}=K_{s f_{1}}\left(z_{b}-z_{w f_{1}}-a \theta_{b}\right)+C_{s f_{1}}\left(\dot{z}_{b}-\dot{z}_{w f_{1}}-a \dot{\theta}_{b}\right)-K_{t f_{1}}\left(z_{w f_{1}}-x_{f_{1}}\right)-C_{t f_{1}}\left(\dot{z}_{w f_{1}}-\dot{x}_{f_{1}}\right) \\
& M_{w f_{2}} \ddot{z}_{w f_{2}}=K_{s f_{2}}\left(z_{b}-z_{w f_{2}}-b \theta_{b}\right)+C_{s f_{2}}\left(\dot{z}_{b}-\dot{z}_{w f_{2}}-b \dot{\theta}_{b}\right)-K_{t f_{2}}\left(z_{w f_{2}}-x_{f_{2}}\right)-C_{t f_{2}}\left(\dot{z}_{w f_{2}}-\dot{x}_{f_{2}}\right)
\end{aligned}
$$




$$
\begin{aligned}
& M_{w r_{2}} \ddot{z}_{w r_{2}}=K_{s r_{2}}\left(z_{b}-z_{w r_{2}}+c \theta_{b}\right)+C_{s r_{2}}\left(\dot{z}_{b}-\dot{z}_{w r_{2}}+c \dot{\theta}_{b}\right)-K_{t r_{2}}\left(z_{w r_{2}}-x_{r_{2}}\right)-C_{t r_{2}}\left(\dot{z}_{w r_{2}}-\dot{x}_{r_{2}}\right) \\
& M_{w r_{1}} \ddot{z r}_{w r_{1}}=K_{s r_{1}}\left(z_{b}-z_{w r_{1}}+d \theta_{b}\right)+C_{s r_{1}}\left(\dot{z}_{b}-\dot{z}_{w r_{1}}+d \dot{\theta}_{b}\right)-K_{t r_{1}}\left(z_{w r_{1}}-x_{r_{1}}\right)-C_{t r_{1}}\left(\dot{z}_{w r_{1}}-\dot{x}_{r_{1}}\right)
\end{aligned}
$$

According to equation (1) the system motion dynamics can be rewritten in matrix considering the following matrices:

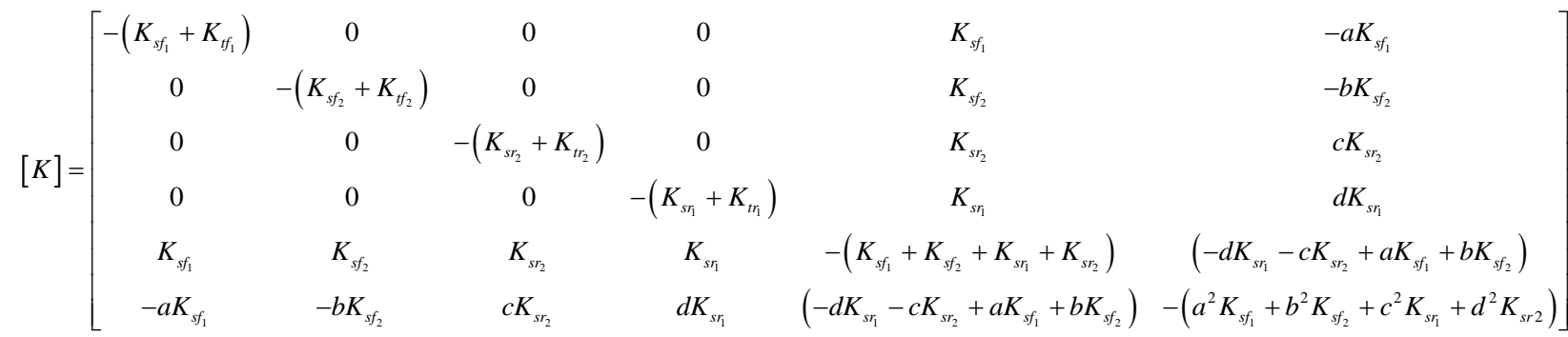

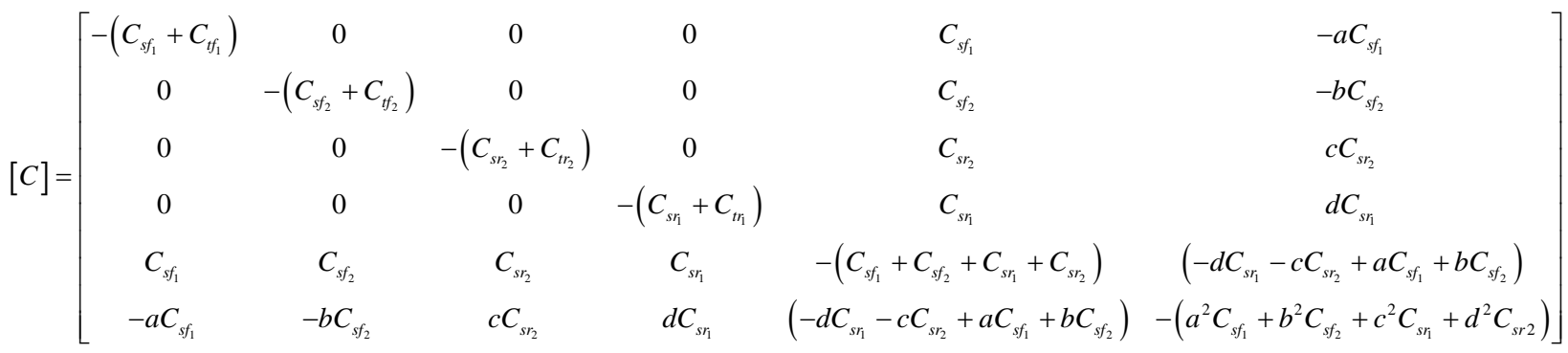

$[M]=\left(\begin{array}{cccccc}M_{w f_{1}} & 0 & 0 & 0 & 0 & 0 \\ 0 & M_{w f_{2}} & 0 & 0 & 0 & 0 \\ 0 & 0 & M_{w r_{2}} & 0 & 0 & 0 \\ 0 & 0 & 0 & M_{w r_{1}} & 0 & 0 \\ 0 & 0 & 0 & 0 & M_{b} & 0 \\ 0 & 0 & 0 & 0 & 0 & I_{b}\end{array}\right)\left[K_{f}\right]=\left(\begin{array}{cccc}K_{t f_{1}} & 0 & 0 & 0 \\ 0 & K_{t f_{1}} & 0 & 0 \\ 0 & 0 & K_{t r_{2}} & 0 \\ 0 & 0 & 0 & K_{t r_{1}} \\ 0 & 0 & 0 & 0 \\ 0 & 0 & 0 & 0\end{array}\right)\left[C_{f}\right]=\left(\begin{array}{cccc}C_{t f_{1}} & 0 & 0 & 0 \\ 0 & C_{t f_{1}} & 0 & 0 \\ 0 & 0 & C_{t r_{2}} & 0 \\ 0 & 0 & 0 & C_{t r_{1}} \\ 0 & 0 & 0 & 0 \\ 0 & 0 & 0 & 0\end{array}\right)$

The vehicle parameters which are used for this paper are given in table (1), see Appendix-A.

\section{Random Road Excitation}

Road surface irregularities can be represented by several waveforms such as sinusoidal, triangular, step input or random roads. These forms are applied to the wheels as a disturbance from ground and the vehicle body response can be evaluated either in time or frequency domains [7]. In this paper, the random road profile is expressed by equation $(8)[8,9]$ which relates the amplitude of excitation $\left(x_{r}\right)$ and its derivative $\left(\dot{X}_{r}\right)$ to road irregularities and 
vehicle speed ( $V$ ). The white noise is given by $\left(\omega_{n}=2 \sigma^{2} \rho V\right)$ where $(\rho)$ is the road roughness parameter and it depends upon road condition, while $\left(\sigma^{2}\right)$ is the covariance of road irregularity. The values of road surface irregularity $\left(\rho=0.45 \mathrm{~m}^{-1} \& \sigma^{2}=300 \mathrm{~mm}^{2}\right)$ are selected assuming the vehicle moves with constant speed $v=36(\mathrm{Km} / \mathrm{hr})$ as shown in Fig. 3.

$$
\dot{X}_{r}+\rho V X_{r}=V \omega_{n}
$$

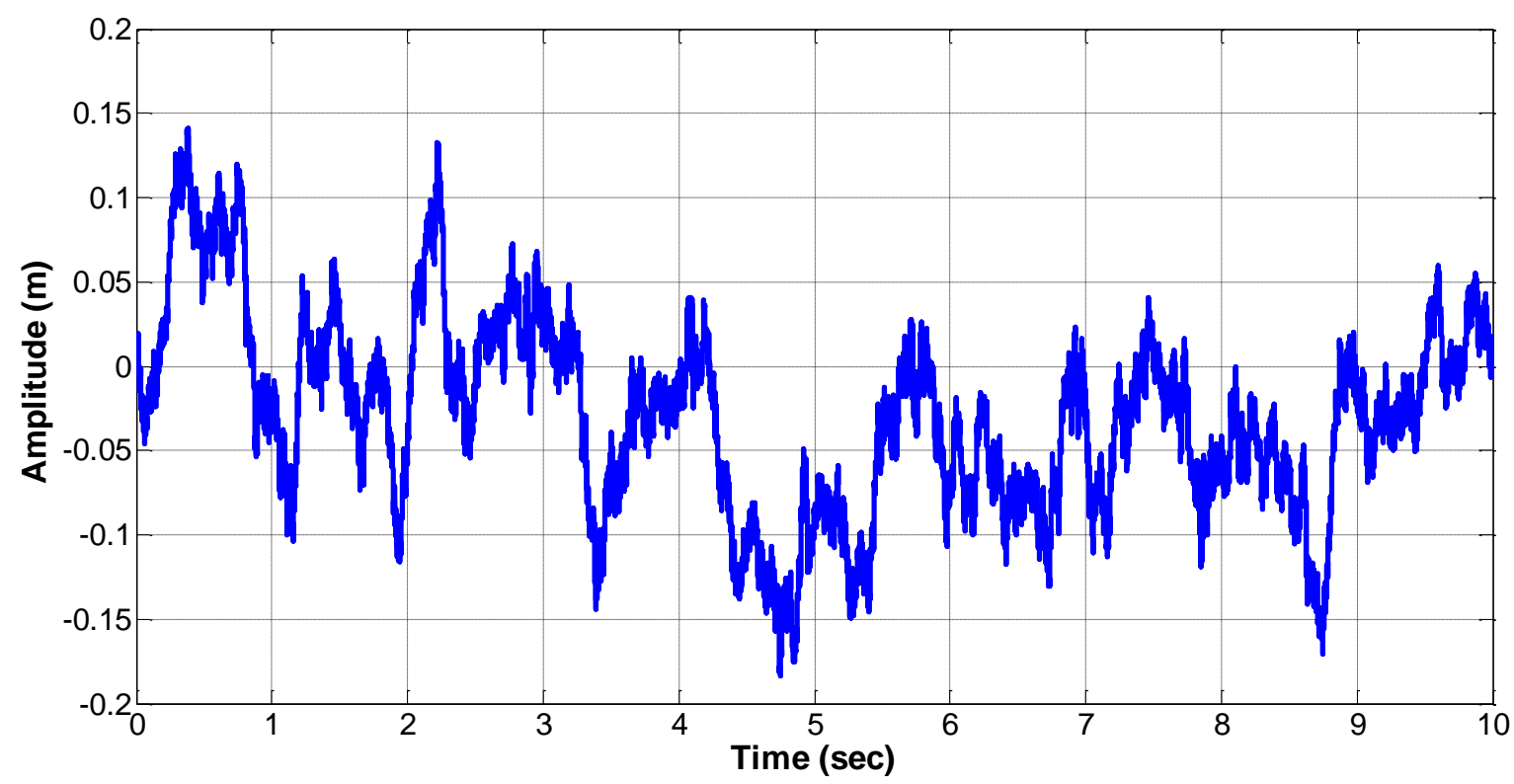

Fig. 3. Random Road Profile.

\section{Results and Discussion}

It is commonly recognized that, the dynamics of both sprung and un-sprung masses greatly affects both the ride and handling. Higher vertical sprung mass acceleration and displacement affect the ride comfort while higher un-sprung mass displacement affects the vehicle stability. To improve vehicle stability wheel contact forces must be increased [10]. In this paper, three models are developed to investigate the effect of the number of axles on the ride response. These models are implemented in MATLAB/SIMUINK environment and the results are compared. The total spring stiffness and damping coefficient of the suspension systems are equal in each model.

\subsection{Vehicle Body Ride Comfort}

The variation of the power spectral density of the vertical acceleration of the vehicle body for different number of axles is shown in Fig. 4. The forces generated by road surface irregularities (bumps) must be overcome by the springs in order to keep tires in contact with the road. The force of the springs comes from the compressive load imposed by the weight of the vehicle. The lighter the vehicle, the less compressive force is available, and the easier it is for the vertical motion of the wheels to overcome the inertia of the sprung mass and the 
transfer vertical \& pitch motions to it as well. It should be noted that increasing the number of axles reduces the total sprung mass weight; therefore the four-axle vehicle has the lightest sprung mass weight than the three and the two-axle vehicle. As a result for what mentioned above, the four-axle vehicle is greatly improves the body vertical acceleration and consequently its ride response. Referring to table (2) and in comparison with the vehicle with two axles, the four-axle model reduces the vehicle body vertical acceleration by $19 \%$ while the three-axle model reduces the vehicle body vertical acceleration by $18 \%$.

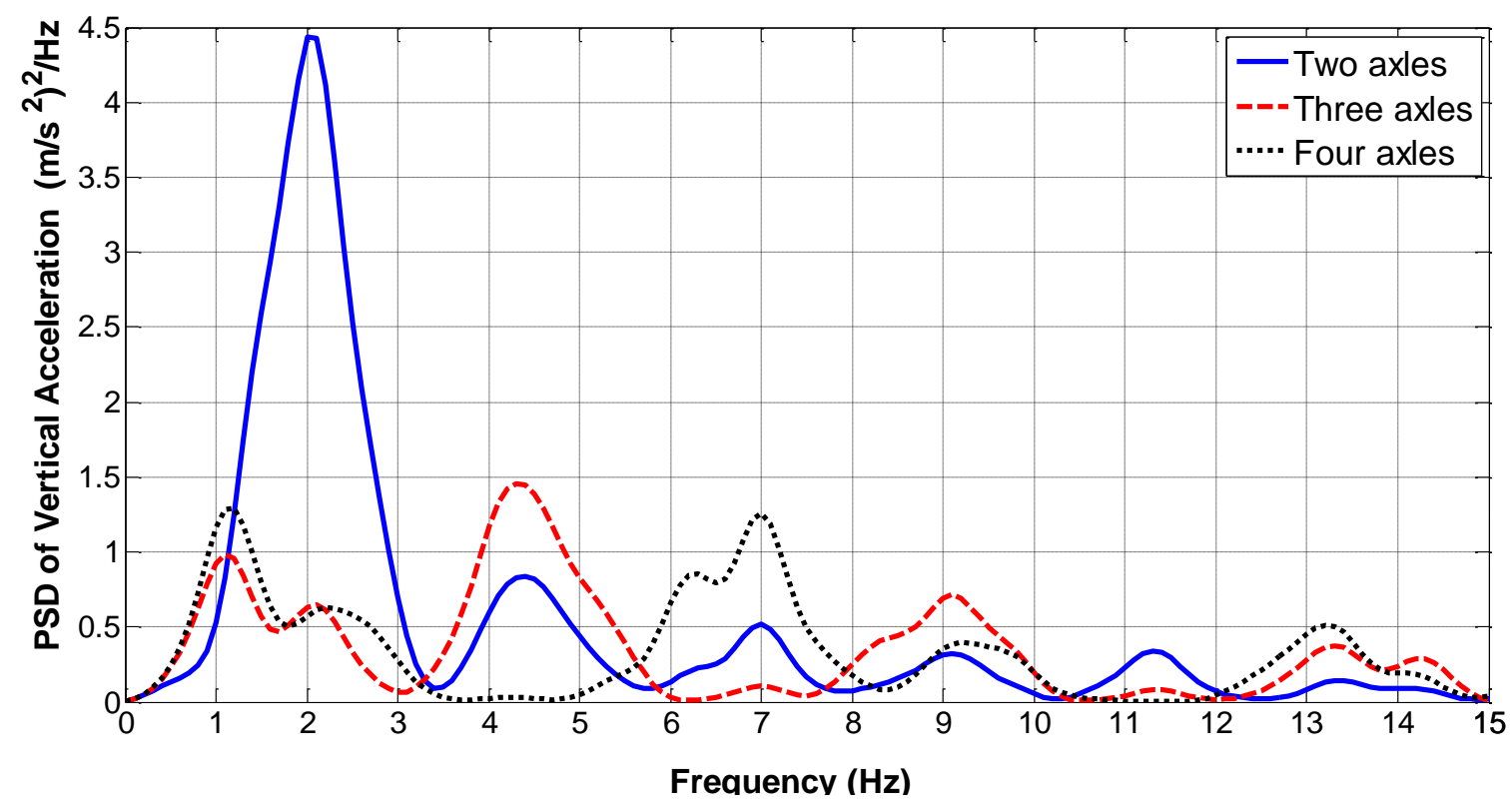

Fig. 4. Vehicle Body Vertical Acceleration at $10 \mathrm{~m} / \mathrm{s}$.

The pitching oscillation of the vehicle body has a large influence on ride comfort. The result of analytical investigation of the pitching response for different number of axles is shown in Fig. 5. The depicted results confirm that increasing the number of axles greatly improves the body pitch acceleration and consequently its ride response. There are $27.8 \%$ and $23 \%$ improvements in root mean square values for the four and three axle vehicle respectively over the two axle vehicle, also there is $4.8 \%$ improvement in root mean square value for the four axle over the three axle vehicle as illustrated in table (2) in Appendix-A. It is clear from the obtained results that, a significant vehicle body ride improvement in terms of vertical acceleration and pitch angular acceleration has been gained for the 4-axle compared to 3-axle and 2-axle. It should be noted that, the obtained results agree with the findings in [6]. 


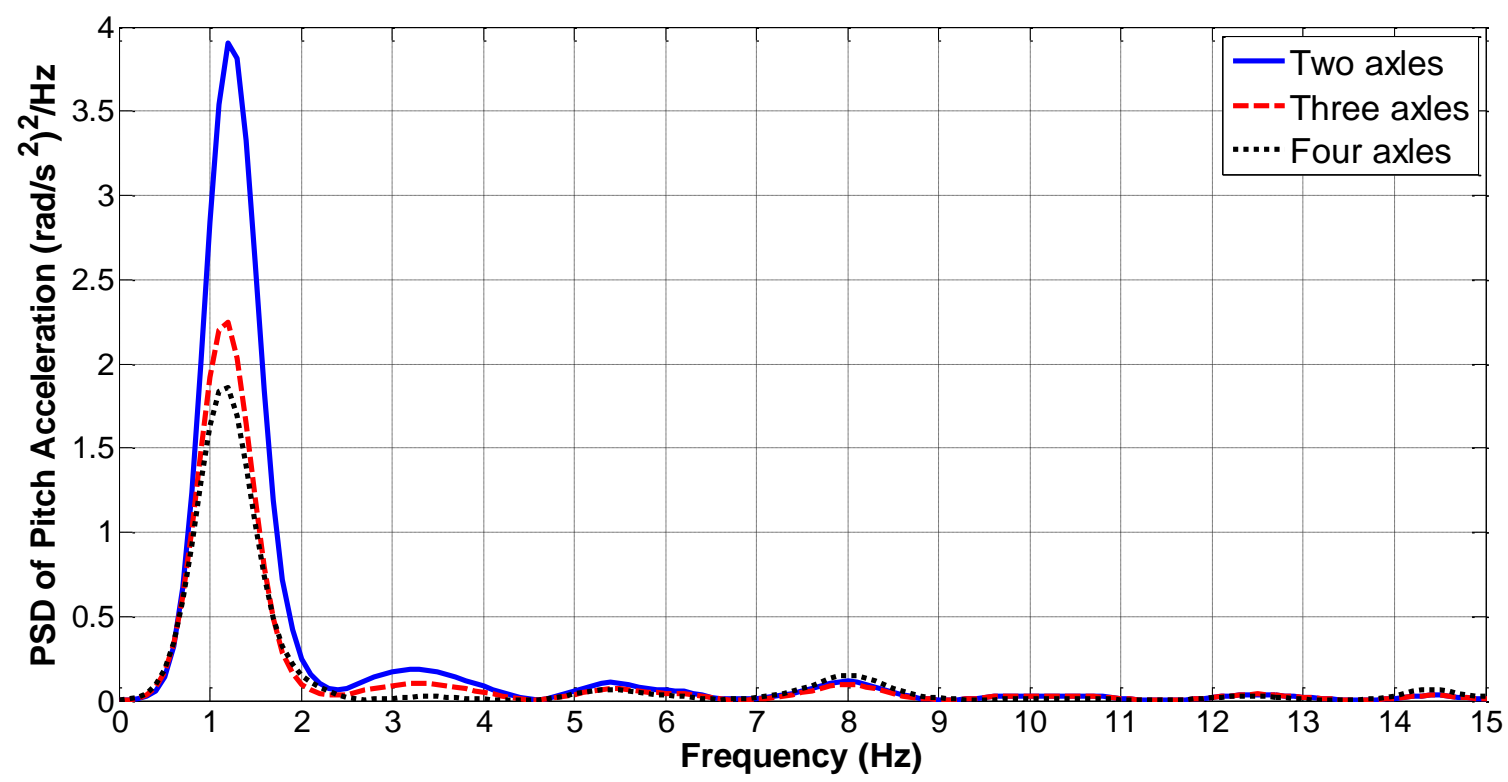

Fig. 5. Vehicle Body Pitch Acceleration at $10 \mathrm{~m} / \mathrm{s}$.

\subsection{Tire Dynamic Load (DTL)}

Tire Dynamic Load (DTL) is an important measure for vehicle performance and cornering stability. Higher DTL indicates poor conditions to maintain the desired vehicle stability. It can be noted from Fig. 6 and Fig. 7 that, the tire dynamic load in both front and rear axles tires is reduced when the vehicle axles are increased and this is because increasing the vehicle number of axles means increasing of the suspension damping. Large suspension and tire damping are both reduce vehicle dynamic tire load. The root mean square of the tire dynamic load is improved by $24 \%$ and $12.9 \%$ for the vehicle with four and three axles respectively compared to that of the vehicle with two axles as shown in table (2). As a result, further improvements are expected in the traction, braking, and the lateral stability of the vehicle.

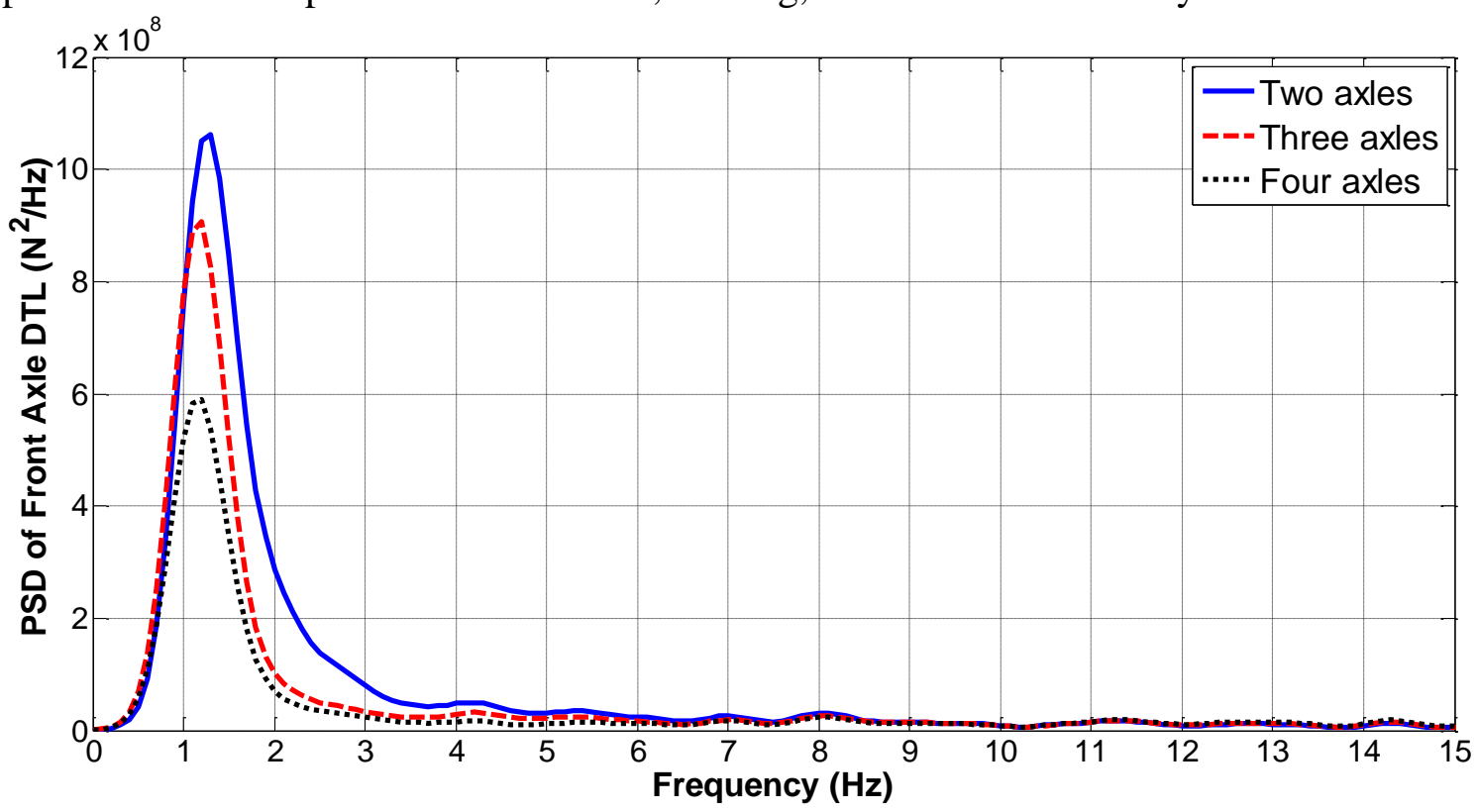

Fig. 6. Front Axle Dynamic Tire Load at $10 \mathrm{~m} / \mathrm{s}$. 


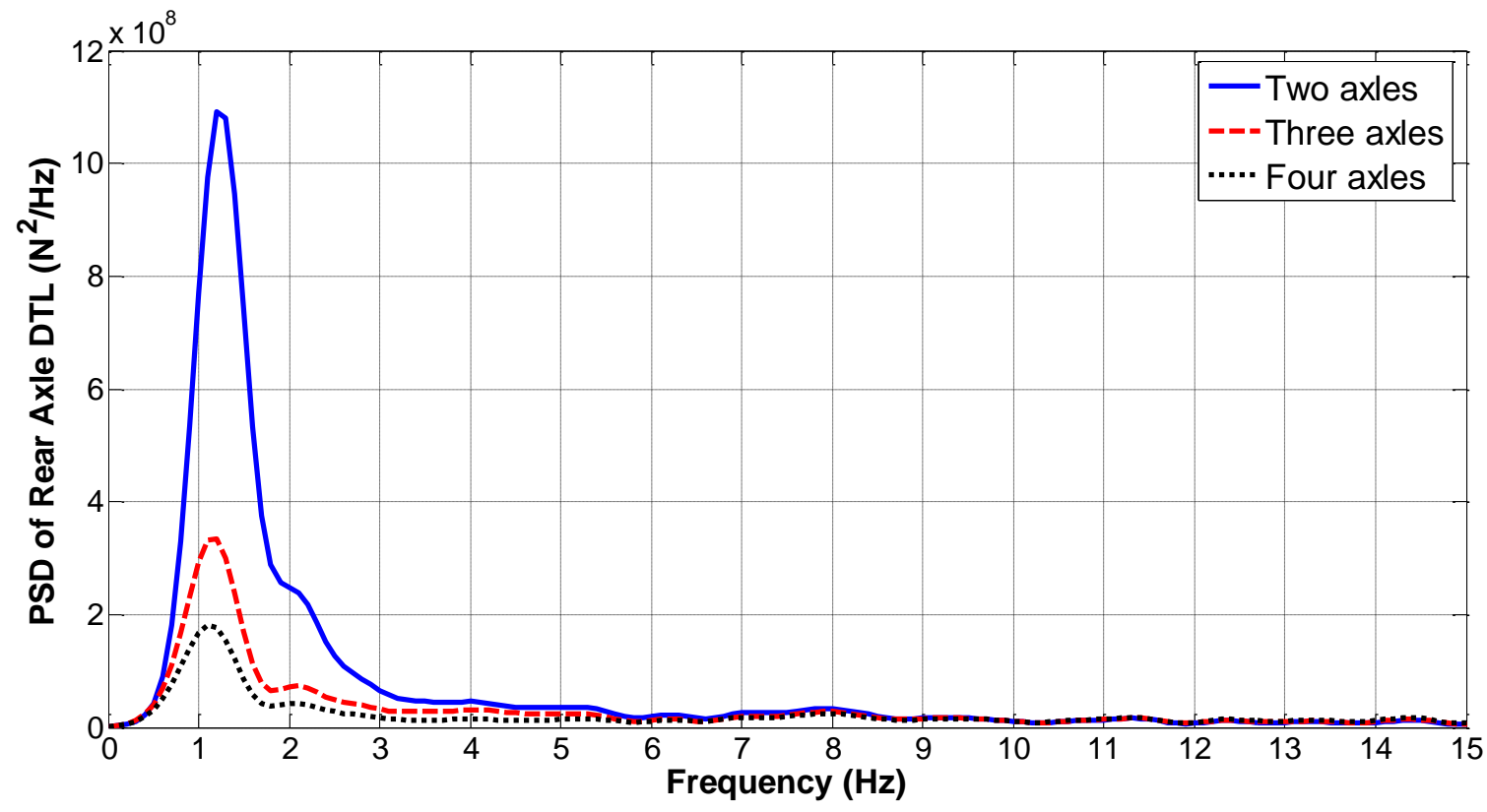

Fig. 7. Rear Axle Dynamic Tire Load at $10 \mathrm{~m} / \mathrm{s}$.

The dynamic tire load for the middle axle of the vehicle with 3 -axle and the second front axle of the vehicle with 4-axles is shown in Fig. 8. It is clear that, the middle axles have a smaller dynamic tire load than that of the front and rear axles, see Fig. 6 and Fig. 7.

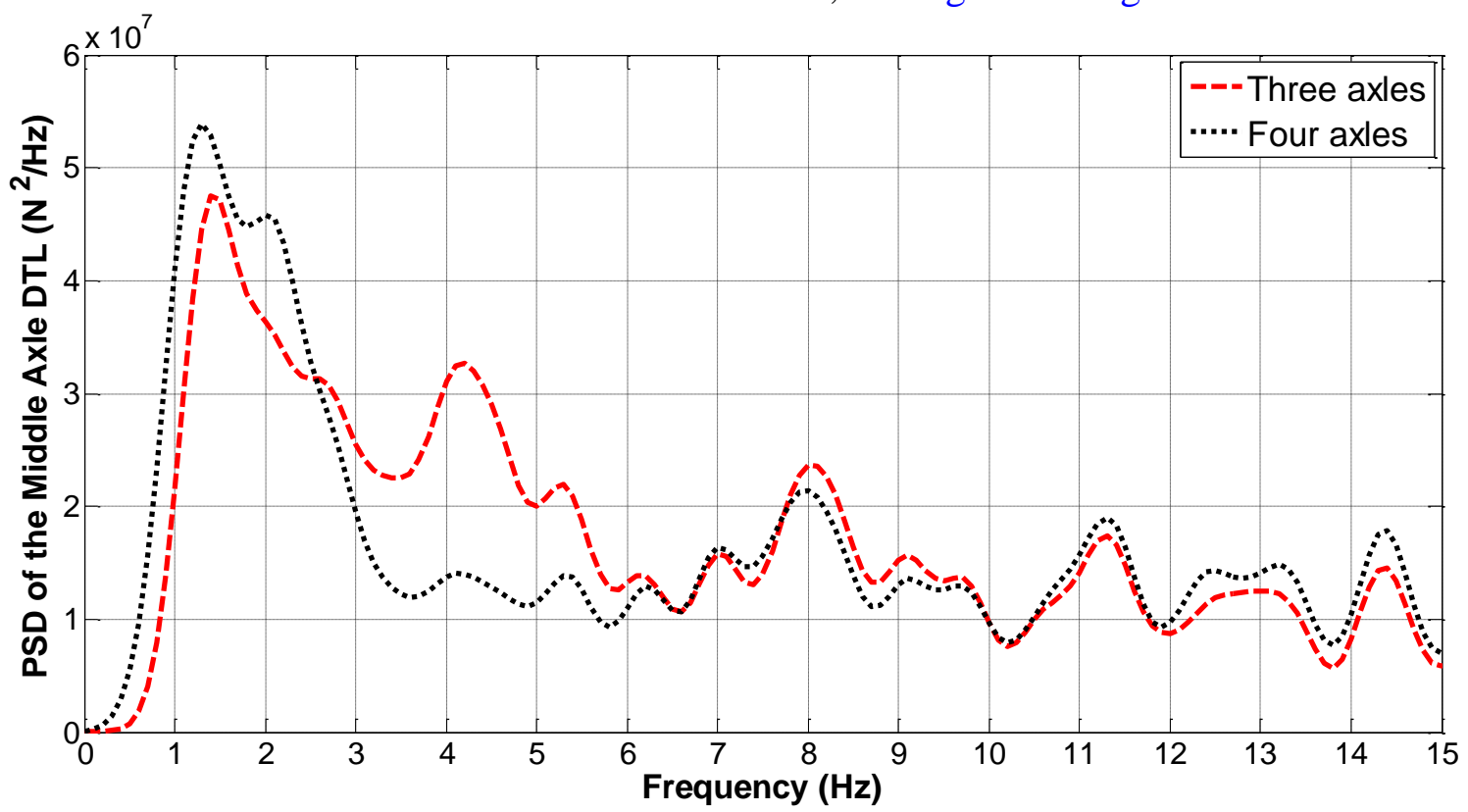

Fig. 8. Middle Axles Dynamic Tire Load at 10 m/s.

\subsection{Suspension Working Space (SWS)}

Suspension working space is a main design parameter which is mainly dependent on the spring softness and consequently affects the ride comfort. In practice, the working space must be restricted according to the vehicle type and layout. Fig. 9 and Fig, 10 show that, the suspension working space of the vehicle with two-axle is significantly less than the of the 
vehicle three and four axles. It is commonly recognized that the ride comfort can be improved at the expense of the suspension working space.

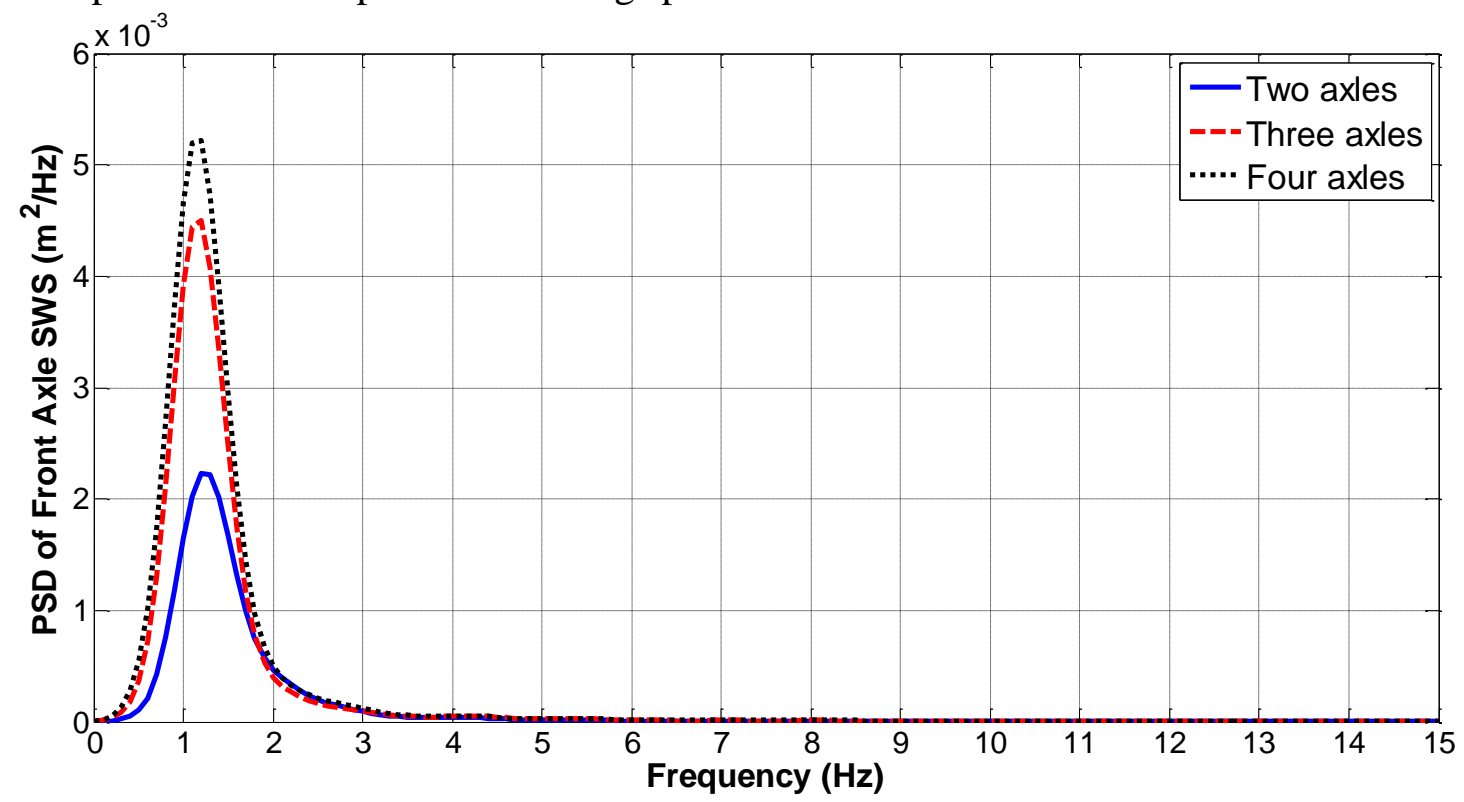

Fig. 9. Front Axle Suspension Working Space at $10 \mathrm{~m} / \mathrm{s}$.

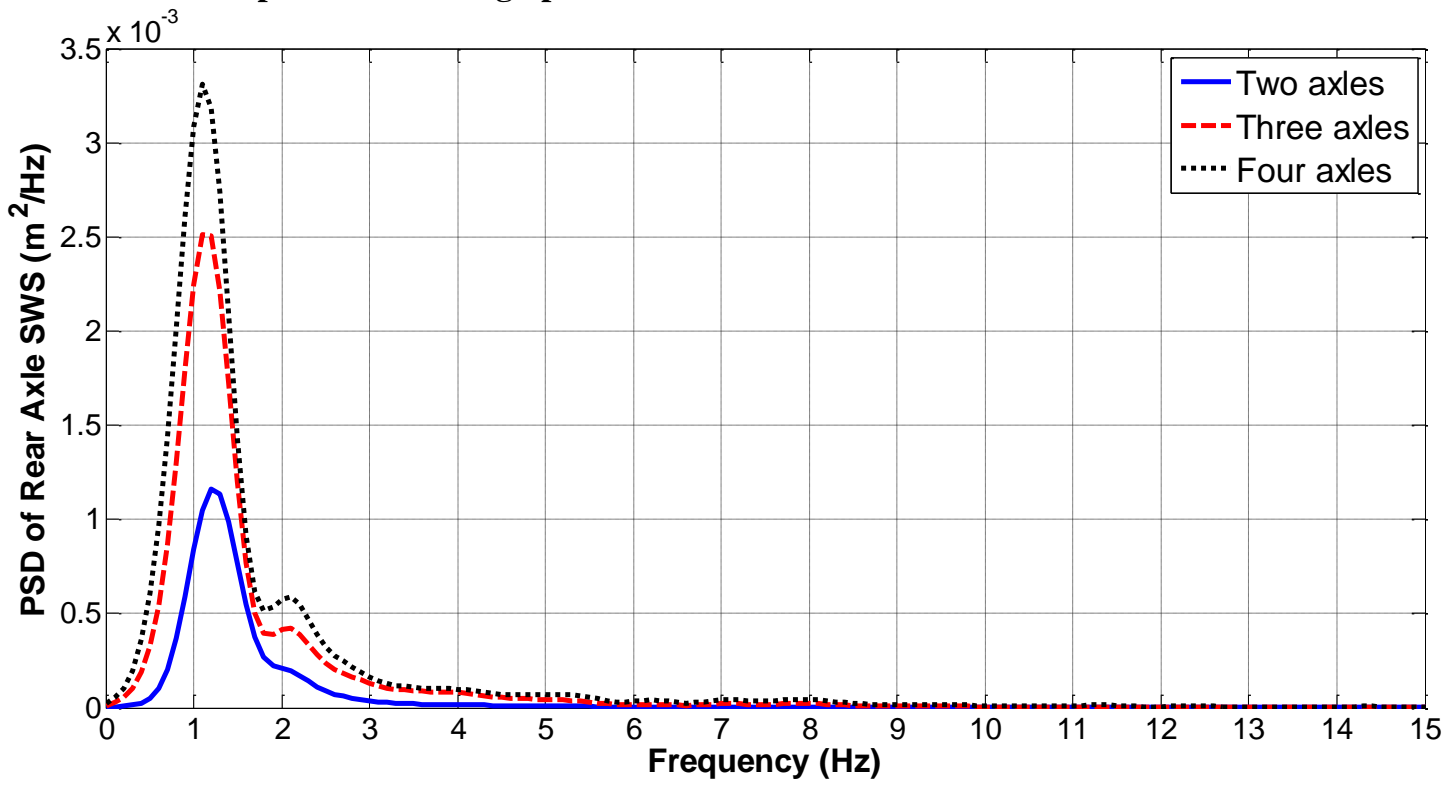

Fig. 10. Rear Axle Suspension Working Space at 10 m/s.

Fig. 11 shows the PSD of the middle axle suspension working space in the three-axle vehicle and the second front axle in the four-axle vehicle. This figure indicates that the middle axle of the three-axle vehicle has a smaller suspension working space than the four-axle vehicle which confirms the results represented in Fig. 8 and Fig. 9. 


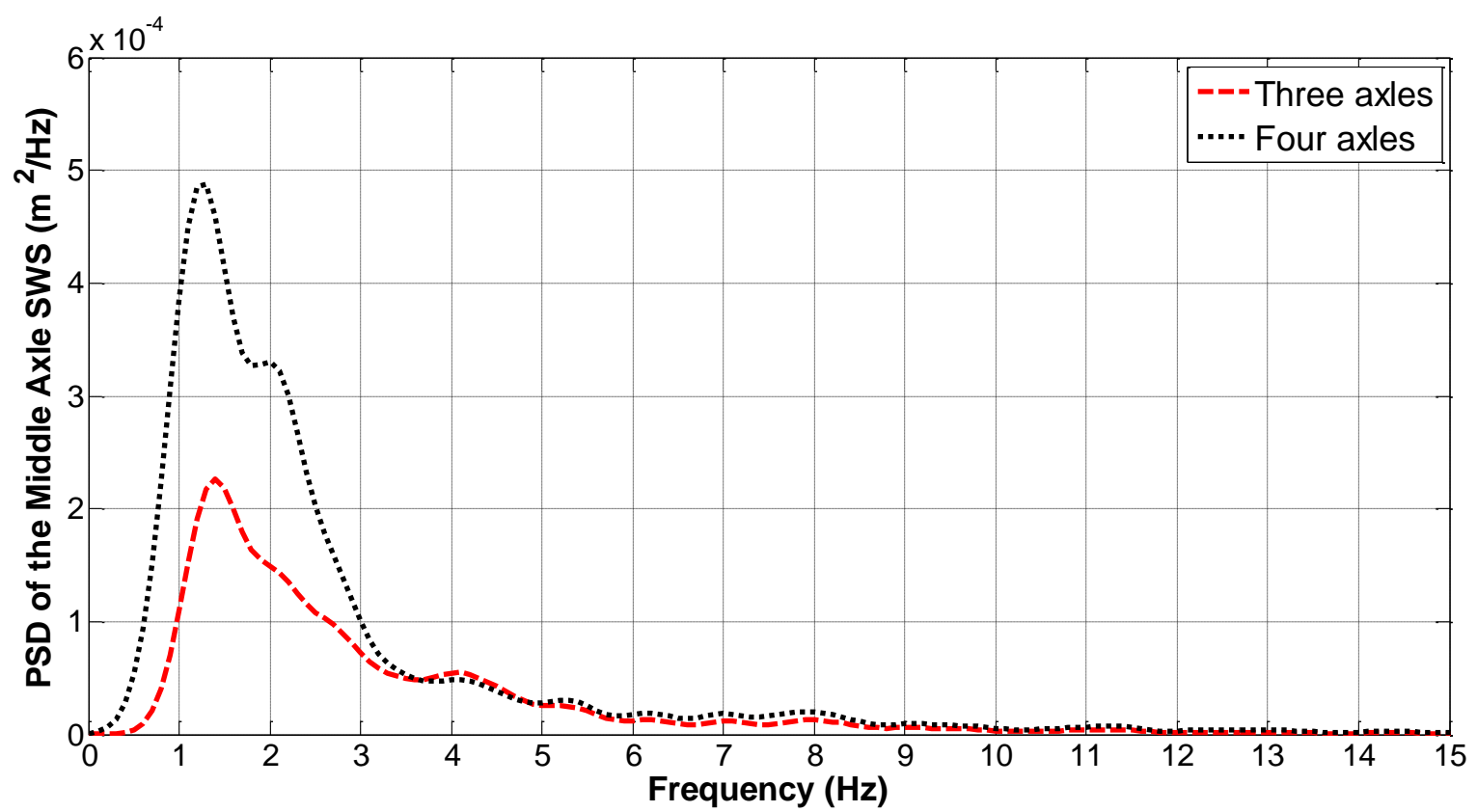

Fig. 11. Middle Axles Suspension Working Space at 10 m/s.

\section{Conclusion}

The quality of the ride response of a typical multi-wheeled combat vehicle is assessed in a pitch-bounce plane considering passenger discomfort, dynamic tire load, and suspension working space parameters. Different choices of the number of axles are made in order to map their effect on the ride comfort and vehicle stability. The results show an improvement in ride comfort and vehicle stability using four-axle vehicle model over three-axle and two-axle models. Also it is clear from results that the middle axle in three-axle and four-axle vehicle have a smaller suspension working spaces than front and rear axles because they are close to the vehicle body C.G, also they have a smaller dynamic tire loads compared with the front and rear axles.

\section{References}

[1] Syabillah Sulaiman, Pakharuddin Mohd Samin, Hishamuddin Jamaluddin, Roslan Abd Rahman, Mohammad Safwan Burhaumudin."Modeling and Validation of 7-DOF Ride Model for Heavy Vehicle" International Conference on Automotive, Mechanical and Materials Engineering (ICAMME'2012) Penang (Malaysia) May 19-20, 2012.

[2] Andrew Deakin, David Crolla, Scott Roberts, "Development of a Semi-Active Suspension for a 6x6 Combat Support vehicle", FISITA World Automotive Congress June 12-15, 2000, Seoul, Korea.

[3] S. M. El-Demerdash and E. M. A. Rabeih. "Ride Performance Analysis of Multi-Axle Combat Vehicles" SAE Technical Paper Series 2004-01-2079.

[4] J. Y. Wong." Theory of Ground Vehicles" Third Edition.

[5] Waleed F Faris, "Analysis of semi-active suspension systems for four-axles off-road vehicle using half model" Int. J. Vehicle Noise and Vibration, Vol. 5, Nos. 1/2, 2009.

[6] Waleed F Faris, Zohir Benlahcene and S.I. Ihsan, "Ride Comfort Assessment in Off Road Vehicles using passive and semi-active suspension”, Asia pacific Conference on 
Defense \& Security Technology (DSTC 2009) 6-7th October, 20009, Hotel Istana, Kuala Lumpur, Malaysia

[7] Hamid D. Taghirad and E. Esmailzadeh, "Automobile Passenger Comfort Assured Through LQG/LQR Active Suspension" Journal of Vibration and Control, 1998, 4, 603.

[8] Wael Galal Kotb Ata, "Intelligent Control of Tracked Vehicle Suspension", PhD Thesis, Faculty of Engineering and Physical Sciences, University of Manchester, 2014.

[9] Hassan Metered, Philip Bonello and S Olutunde Oyadiji, "An investigation into the use of neural networks for the semi-active control of a Magnetorheologically damped vehicle suspension', Journal of Automobile Engineering, 2010, Volume: 224 (7), pp 829-848.

[10] Ansar Mulla, Sudhindra Jalwadi and Deepak Unaune,"Performance Analysis of Skyhook, Groundhook and Hybrid Control Strategies on Semiactive Suspension System", International Journal of Current Engineering and Technology, ISSN 22774106, 2014.

\section{APPENDIX-A}

Table (1): Parameters of system model [4]

\begin{tabular}{|l|l|c|c|}
\hline \multicolumn{1}{|c|}{ Model parameters } & \multicolumn{1}{c|}{ Symbol } & Value & Units \\
\hline Vehicle body mass & $\mathrm{M}_{\mathrm{b}}$ & 13200 & $\mathrm{Kg}$ \\
\hline Front axles masses & $\mathrm{M}_{\mathrm{wf} 1}, \mathrm{M}_{\mathrm{wf} 2}$ & 200 & $\mathrm{Kg}$ \\
\hline Rear axles masses & $\mathrm{M}_{\mathrm{wr} 1}, \mathrm{M}_{\mathrm{wr} 2}$ & 200 & $\mathrm{Kg}$ \\
\hline Suspension spring stiffness & $\mathrm{K}_{\mathrm{sf} 1}, \mathrm{~K}_{\mathrm{sf} 2}, \mathrm{~K}_{\mathrm{sr} 1}, \mathrm{~K}_{\mathrm{sr} 2}$ & 300 & $\mathrm{KN} / \mathrm{m}$ \\
\hline Suspension damping coefficients & $\mathrm{C}_{\mathrm{sf1}}, \mathrm{C}_{\mathrm{sf} 2}, \mathrm{C}_{\mathrm{sr} 1}, \mathrm{C}_{\mathrm{sr} 2}$ & 20 & $\mathrm{KN} . \mathrm{s} / \mathrm{m}$ \\
\hline Tire vertical stiffness & $\mathrm{K}_{\mathrm{tf} 1}, \mathrm{~K}_{\mathrm{tf} 2}, \mathrm{~K}_{\mathrm{tr} 1}, \mathrm{~K}_{\mathrm{tr} 2}$ & 1200 & $\mathrm{KN} / \mathrm{m}$ \\
\hline Tire damping coefficients & $\mathrm{C}_{\mathrm{tf} 1}, \mathrm{C}_{\mathrm{t} 22}, \mathrm{C}_{\mathrm{tr} 1}, \mathrm{C}_{\mathrm{tr} 2}$ & $\mathrm{Neglected}$ & - \\
\hline Distance from CG to the first front axle & $\mathrm{a}$ & 2.2 & $\mathrm{~m}$ \\
\hline Distance from CG to the second front axle & $\mathrm{b}$ & 0.85 & $\mathrm{~m}$ \\
\hline Distance from CG to the second rear axle & $\mathrm{c}$ & 0.85 & $\mathrm{~m}$ \\
\hline Distance from CG to the first rear axle & $\mathrm{d}$ & 2.2 & $\mathrm{~m}$ \\
\hline vehicle body mass moment of inertia & $\mathrm{I}_{\mathrm{b}}$ & 70000 & $\mathrm{kgm}$ \\
\hline
\end{tabular}


Table (2): Root mean square (rms) of output parameters for different vehicle models at speed of $10 \mathrm{~m} / \mathrm{s}$

\begin{tabular}{|c|c|c|c|c|c|}
\hline \multirow{2}{*}{ Output parameters } & \multirow{2}{*}{ Units } & \multicolumn{3}{|c|}{ Vehicle Models } & \multirow{2}{*}{ Improvement \% } \\
\cline { 3 - 5 } & & Two-axle & Three-axle & Four-axle & \\
\hline$\ddot{Z}_{\mathrm{b}}$ & $\mathrm{m} / \mathrm{s}^{2}$ & 2.87 & 2.33 & 2.32 & $19 \%$ \\
\hline$\ddot{\Theta}_{\mathrm{b}}$ & $\mathrm{rad} / \mathrm{s}^{2}$ & 1.87 & 1.44 & 1.35 & $27.8 \%$ \\
\hline SWSf1 & $\mathrm{m}$ & 0.0449 & 0.059 & 0.0651 & - \\
\hline SWSc & $\mathrm{m}$ & - & 0.0216 & - & - \\
\hline SWSr2 & $\mathrm{m}$ & - & - & 0.0298 & - \\
\hline SWSr1 & $\mathrm{m}$ & 0.023 & 0.0607 & 0.082 & - \\
\hline DTLf1 & $\mathrm{N}$ & 36159 & 31482 & 27464 & $24 \%$ \\
\hline DTLc & $\mathrm{N}$ & - & 19090 & - & - \\
\hline DTLr2 & $\mathrm{N}$ & - & - & 19094 & - \\
\hline DTLr1 & $\mathrm{N}$ & 36783 & 24816 & 21343 & $42 \%$ \\
\hline
\end{tabular}

Table (3): Undamped natural frequencies \& associated modes

\begin{tabular}{|c|c|c|c|c|}
\hline \multirow{2}{*}{ Mode number } & \multicolumn{3}{|c|}{ Undamped natural frequencies (Hz) } & Mode type \\
\cline { 2 - 5 } & Two-axle & Three-axle & Four-axle & \\
\hline 1 & 1.182 & 1.0242 & 0.9823 & Body pitch \\
\hline 2 & 1.22 & 1.3024 & 1.356 & Body bounce \\
\hline 3 & 15.122 & 14.235 & 13.783 & $1^{\text {st }}$ wheel bounce \\
\hline 4 & 15.124 & 14.2476 & 13.783 & $2^{\text {nd }}$ wheel bounce \\
\hline 5 & - & 14.2553 & 13.792 & $3^{\text {rd }}$ wheel bounce \\
\hline 6 & - & - & 13.8 & $4^{\text {th }}$ wheel bounce \\
\hline
\end{tabular}

